\title{
Linguagem, discurso e cognição: desafios e perspectivas
}

\author{
Sandra Cavalcante* \\ Ana Margarida Abrantes** \\ André Luiz Souza***
}

Desde a Antiguidade Clássica, a relação entre linguagem e interação social, entre linguagem e cultura, entre linguagem e diferentes formas de conhecimento é uma preocupação que se explicita, de maneira evidente, na história da filosofia. Partindo dos sofistas, passando por Platão e Aristóteles, até chegarmos a filósofos contemporâneos como Wittgenstein, Heidegger, Derrida, Foucault, entre outros, são múltiplos os caminhos que o fenômeno da linguagem percorre quando tomado como objeto de reflexão. ${ }^{1}$

Se pensarmos na cognição e na comunicação como duas faces de uma só moeda, podemos entender a linguagem como a interface metálica que liga os dois lados. A análise linguística é um instrumento privilegiado para aceder a estruturas de pensamento, a formas de organização conceptual e ao modo como produzimos sentido a partir da experiência perceptual ou de estímulos de abstração. Ao mesmo tempo, pelo uso da língua, a linguagem manifesta-se em instâncias de discurso, ou seja, de expressão estilizada e socialmente estruturada, reveladora da estruturação intersubjetiva do pensamento: a análise da linguagem, estruturada em discurso, no processo enunciativo, revela como o interlocutor está frequentemente previsto e mesmo incluído no modo como pensamos sobre a realidade e a referenciamos linguisticamente.

As concepções de linguagem e de cognição aqui subjacentes nos permitem considerar, em consonância com Benveniste, que "o ato individual pelo qual se utiliza a língua introduz em primeiro lugar o locutor como parâmetro nas condições necessárias de enunciação", ou seja, por um ato individual, nos apropriamos

\footnotetext{
*Pontifícia Universidade Católica de Minas Gerais. Instituto de Ciências Humanas. Programa de Pós-Graduação em Letras (Brasil).

** Universidade Católica Portuguesa. Faculdade de Ciências Humanas. Centro de Estudos de Comunicação e Cultura (Portugal).

***Assistant Professor, Department of Psychology, The University of Alabama (USA).
}

1 Martins, 2004, p. 439-472. 
da língua (de suas convenções simbólicas) e a mobilizamos criativamente. A enunciação, nessa perspectiva, pressupõe o próprio ato, as situações em que ele se realiza e os instrumentos (fonológicos, lexicais, gramaticais, semânticos) de sua realização. ${ }^{2}$ Se o ato de colocar a língua em atividade é desencadeado por locutores empíricos que, em um dado contexto comunicativo, necessitam referir e correferir pelo discurso, a análise linguística, assumida em uma perspectiva cognitiva, não deve abrir mão do desafio de considerar a relação existente entre as diferentes dimensões da linguagem (e da vida) humana.

Entre a forma como pensamos e os discursos que produzimos, há um largo espectro de influência dialética. E essa influência se dá por uma dinâmica e inextricável relação entre as estruturas universais da cognição, assentes numa base neurobiológica comum, e a cultura que orienta, modela e edita essas estruturas. Esse continuum entre cognição e cultura torna o pensamento humano um elemento constitutivo, fundamental, para a experiência humana no campo da arte e da ciência. A sua abordagem é, necessariamente, uma tarefa transdisciplinar, que interessa e ocupa as humanidades, as ciências naturais e sociais, aproximando diferentes áreas do conhecimento humano.

Trabalhos de pesquisa, de natureza empírica, realizados nos campos da Antropologia Evolucionária e da Psicologia Cognitiva, nas últimas décadas do século XX, apresentam evidências científicas que corroboram a tese de que a cognição humana é marcada por processos, simultaneamente, filogenéticos, históricos e ontogenéticos que permitem ao homem beneficiar-se das diversas formas de conhecimento acumuladas pelos grupos sociais e que, ao mesmo tempo, determinam essas diversas formas de conhecimento, entre elas, a própria comunicação linguística. ${ }^{3}$

A evolução cultural humana é, definitivamente, cumulativa. Desenvolvemos, utilizamos, compartilhamos e perpetuamos o nosso potencial cognitivo em meio a artefatos e práticas sociais que reúnem a memória social da espécie humana, ou seja, toda experiência e sabedoria coletiva acumulada pelos grupos sociais a que pertencemos. Nossa percepção, atenção, memória, nossa capacidade de categorizar, de perspectivar, de criar analogias e metáforas, de resolver problemas, de referenciar e de significar, através do uso comunicativo, estético e religioso de símbolos linguísticos e não linguísticos, criados e compartilhados culturalmente, enfim, nossa cognição é impactada e parametrizada pelas nossas vivências culturais, pelas nossas experiências sociais. Estas, por sua vez, se instituem, 
desde a mais tenra infância, de maneira subjetiva, pessoal, idiossincrática e, simultaneamente, de maneira intersubjetiva, compartilhada, conjunta, coletiva. Evolutivamente, atuamos (cada vez mais) em coletividades cognitivas, em simbioses com sistemas externos de memória. À medida que desenvolvemos novas configurações simbólicas externas e novas modalidades (e nos apropriamos destas), reconstruímos a nossa própria arquitetura mental de uma forma nada trivial. $^{4}$

A linguagem humana é, portanto, reveladora dessa inextricável relação entre cognição e cultura e, assim sendo, um objeto de análise, que coloca pesquisadores de diversas áreas e linguistas, em particular, frente ao desafio de investigá-la entre o universalismo da cognição e o relativismo da cultura. A linguagem humana, manifestada nas diversas formas de uso das línguas naturais, é interpessoalmente objetiva, o que permite generalizações sobre a dimensão partilhada da cognição. Por outro lado, ela é simultaneamente flexível, de modo a acomodar produções discursivas individualizadas, em constelações intersubjetivas diferentes e contextos sociais distintos.

Entre o partilhado e o particular, subjacente ao exercício concreto da (inter) subjetividade, da dialogicidade - concretizado nos processos de estruturação linguística e de interação discursiva - o desafio de investigação da linguagem humana, em diferentes perspectivas e dimensões, vem sendo histórica e sistematicamente assumido por pesquisadores que atuam em centros de excelência acadêmica de diferentes nacionalidades.

Nesse contexto desafiador e prospectivo, apresentamos o número 34 da Revista Scripta, uma edição temática organizada com base em resultados de pesquisas que privilegiam a relação intrínseca entre Linguagem, Discurso e Cognição. Esta edição temática está estruturada em cinco partes, que refletem uma organização de temas e de tipos de textos, entre artigos, resenhas e entrevistas.

Os trabalhos aqui apresentados exploram a intersecção entre pensamento e linguagem, por um lado, e cognição e comunicação, por outro, incidindo, ainda, sobre a multimodalidade e a mediação tecnológica no processo comunicativo, bem como sobre a dimensão compartilhada da cognição humana. Entre os temas abordados estão as relações entre "linguagem e processos de estruturação e mudança linguística", "linguagem e mídia", "linguagem e polissemia" e ainda "linguagem e figuração".

Os textos que integram a primeira parte centram-se em fenômenos implicados na relação entre processos de estruturação linguística e cognição, em diferentes 
línguas. Abrindo esta parte, Sueli Coelho e Silmara Silva sistematizam resultados de pesquisa relativos ao processo de gramaticalização do verbo DAR na língua portuguesa, em uma perspectiva diacrônica. Constatando que, ao longo dos séculos, o verbo DAR muda de categoria, passando de predicador a auxiliar, as pesquisadoras atribuem essa multifuncionalidade ao processo cognitivo de abstração semântica, o que permite traçar um continuum da mudança gramatical do verbo. Segundo as autoras, esse é um processo cognitivo que deve ser considerado no percurso da história linguística do verbo, uma vez que permite explicar a perda de algumas das suas propriedades gramaticais em detrimento da incorporação de outras - como a expressão da modalidade e a marcação do aspecto verbal. O estudo é, assim, uma abordagem diacrônica a um aspeto linguístico revelador da forma como necessidades de expressão alteram formas de conceptualização.

Em artigo dedicado à análise do processo de categorização implicado no uso de interjeições frente ao de onomatopeias e de sons inarticulados, Lucía Bernardi investe na análise de dados provenientes de diferentes corpora de língua espanhola, à luz da teoria do protótipo. Bernardi distingue entre o espaço de categorização de interjeições face ao dos outros elementos, propondo ainda a distinção entre o sistema de categorias gramaticais em que se inserem as interjeições, e um sistema de categorias expressivas, em que estão incluídas as onomatopeias e os sons inarticulados. De acordo com a análise de dados apresentada, a autora descreve uma ligação entre os dois sistemas - categorias gramaticais e categorias expressivas - assegurado pela relação que as interjeições, enquanto categorias gramaticais, mantêm com as categorias de sistema expressivo. A função discursiva desses elementos linguísticos é, assim, analisada em paralelo com a sua natureza conceptual, num estudo que articula expressão e conceptualização.

Iraide Ibarretxe-Antuñano, Teresa Cadierno e Alberto Hijazo-Gascón abordam os eventos de colocação (placement events), nos quais uma figura muda de posição pela ação de um agente. Com base numa codificação dos eventos de colocação em línguas tipologicamente distintas, os autores apresentam uma descrição interlinguística (espanhol e dinamarquês), formulando ainda hipóteses sobre dificuldades que falantes nativos dinamarqueses, aprendizes de espanhol como segunda língua, podem encontrar na comunicação sobre esse tipo de evento, bem como estratégias que desenvolvem para proceder a essa comunicação. Numa perspectiva comparativa e aplicada, esse estudo posiciona-se numa linha de investigação sobre variação linguística a partir de um denominador conceptual comum. 
Lilian Ferrari e Diogo Pinheiro exploram um tipo de construção idiomática formal denominada Construção Consecutiva Subjetiva Escalar (CCSE), em exemplos como "Isso é muito bom para ser verdade" (significando que algo não pode ou não deve ser verdade). Integrando o paradigma da Gramática de Construções e a Teoria dos Espaços Mentais, os pesquisadores argumentam que a construção gramatical em estudo ativa um processo de mesclagem conceptual, a partir da compressão de duas escalas análogas, e indica subjetividade, podendo implicar acesso aos domínios (espaços mentais) epistêmico e de ato de fala.

Ao discutir o papel da atenção no processo de produção de sentido desencadeado por textos marcadamente polissêmicos, Kariny Raposo e Helena Magalhães consideram a relação entre significado e consciência. Em particular, as autoras analisam a polissemia como instrumento direcionador da atenção, propondo que os vários sentidos de um significado são elementos invariáveis que a atenção focaliza, diferenciadamente, a partir da experiência consciente.

Os artigos que constituem a segunda parte apresentam resultados de pesquisa centrados em fenômenos implicados na relação entre linguagem, interação discursiva e cognição. Abrindo essa parte, Leland McCleary e Evani Viotti propõem um estudo no âmbito da multimodalidade, ao abordarem narrativas sinalizadas. Os autores discutem a necessidade de que estudos de narrativa dediquem particular atenção às narrativas desenvolvidas na interação face a face e, ainda, que considerem a atuação dos corpos dos participantes da interação um fator constitutivo na construção da significação e na estruturação da narrativa. Neste artigo, ao descrever e analisar uma narrativa sinalizada em língua brasileira de sinais (libras), os pesquisadores defendem sua tese em consonância com trabalhos que buscam a construção de um diálogo entre os estudos da narrativa e a investigação da interação face a face, por um lado, e aqueles que ressaltam a importância do contexto enunciativo para a produção narrativa, por outro. Revelador nesse texto é o contributo que os estudos sobre modalidades linguísticas alternativas podem oferecer à investigação sobre a linguagem e a cognição, nomeadamente ao demonstrarem a natureza situada, corporificada e interpessoal da comunicação e do pensamento humano.

Em seu artigo, Erik Martins propõe uma abordagem teórica e analítica das noções de Contexto e Tópico Discursivo como elementos centrais do trabalho interpretativo dos participantes em uma interação. Essas categorias são centrais na ancoragem e estabilização de significados, nomeadamente referenciais, pela relação que estabelecem entre referência linguística e realidade. Ao focalizar sua análise em estratégias de ação e manipulação tópica empregadas no contexto de 
uma entrevista jornalística, o pesquisador conclui que a relação entre as noções de contexto e tópico discursivo está, fundamentalmente, associada à progressão da interação e ao desenvolvimento de modelos mentais de contexto. $\mathrm{O}$ autor explora ainda os efeitos de sentido decorrentes de estratégias de ação e manipulação tópica identificadas nos dados analisados. Nessa abordagem da interação entre cognição e discurso, o autor centra-se, em particular, em um aspecto dessa interação: a influência do discurso sobre a conceptualização.

Adriana Tenuta, Marcus Lepesqueur e Maria Luiza Lima apresentam resultados de pesquisa que permitem observar como o processo de figuração, em narrativas orais, reflete o princípio cognitivo da percepção humana, em termos da relação figura e fundo, proposta pela Psicologia da Gestalt. Os autores apresentam uma distinção entre eventos que compõem a linha principal da história e que são marcados gramatical e discursivamente como figura, e eventos que não apresentam a mesma saliência, sendo antes marcados como o fundo narrativo que sustenta os elementos centrais da história. A partir da produção de narrativas orais por um grupo de informantes, os autores analisam o processo de figuração, propondo uma relação entre a ocorrência de unidades de figura ou fundo e tarefas com exigência cognitiva diferenciada, de atenção e memória. A correlação observada é a de que as narrativas produzidas a partir de conteúdos de memória apresentam maior número de unidades de fundo, evidenciando maior manipulação de modelos cognitivos e fugindo a uma representação objetiva da realidade. $\mathrm{O}$ artigo aborda, assim, a interligação entre uma função cognitiva não linguística, nomeadamente a percepção, e um tipo de discurso, o discurso narrativo, deixando a sugestão de um continuum entre as várias dimensões da cognição humana. Mais ainda, o artigo abre uma porta interessante à discussão da objetividade em representação, questão antiga e atual em outras áreas, como a ficção (autobiográfica) ou a historiografia.

$\mathrm{Na}$ mesma linha de investigação, analisando a interligação entre processos cognitivos e a prática do discurso, Vera Tobin apresenta um artigo sobre a atenção conjunta em comunidades de leitura. A autora desafia a visão estabelecida em modelos de linguagem de que os escritores e leitores de textos publicados, como o romance, funcionam como falantes e destinatários numa interação, propondo antes que os leitores assumem o papel de ouvintes casuais. Tobin apresenta um modelo que salienta a importância da interação entre os leitores de um mesmo texto, ouvintes casuais que, na interação entre si, colaboram na construção do sentido, num processo que, em grande medida, exclui os autores. Essa interação participada, nas comunidades de leitores é uma manifestação de um processo cognitivo complexo, nomeadamente a atenção conjunta a um mesmo objeto. Esse 
estudo convida à reflexão sobre o impacto de uma cultura popular em expansão, suportada pelas novas possibilidades de comunicação e interação digital, no processo de leitura, criando novas formas de ler e de partilhar a leitura. Além disso, o texto é um indicador da forma como esse universo cultural e tecnológico possibilita a emergência de novas manifestações de processos cognitivos como o da atenção conjunta.

Luciane Ferreira e Pedro Silva investigam, em seu trabalho, a linguagem metafórica em interações discursivas em que o tema é a violência no futebol, no estado brasileiro de Minas Gerais. Na perspectiva adotada pelos pesquisadores, as expressões metafóricas utilizadas pelas pessoas, em situações concretas de interação, refletem suas emoções, valores e opiniões. Os autores partem de dados recolhidos junto a um grupo focal. Refletindo sobre a forma como a violência é conceptualizada, a partir da análise da linguagem metafórica emergente no processo de interação, os autores apontam para a sistematicidade da metáfora conceptual, recursiva em interações discursivas sobre o tema.

Os artigos que constituem a terceira parte apresentam resultados de pesquisa relativos a um dos mais importantes e historicamente estudados fenômenos da linguagem humana: a metáfora. Nessa parte, são apresentados artigos que focalizam a relação entre linguagem, metáfora e cognição, em diferentes perspectivas e enquadramentos teóricos.

Partindo de uma crítica à Teoria da Metáfora Conceptual por essa se basear numa constelação idealizada de interlocutores, em seu artigo, Ulrike Schröder apresenta abordagens que privilegiam o processo de co-construção do significado de expressões metafóricas por falantes e ouvintes, considerando como indissociável, nesse processo, o contexto pragmático, social e cultural em que os interlocutores estão inseridos. Em sua discussão, a pesquisadora busca explicitar o que considera limitações identificadas em estudos psicolinguísticos, textual-discursivos e pragmático-interacionais sobre o fenômeno. Schröder argumenta em favor da tese de que o entendimento do processo da comunicação humana, em termos da coordenação de ações que envolvem funções sistemáticas do interlocutor - seu papel como falante e ouvinte - é um caminho a ser considerado na busca de superação das limitações apresentadas. A autora defende, assim, uma abordagem à metáfora conceptual na perspectiva da construção ativa do significado.

Maíra Miranda e Paulo Mendes analisam a emergência de metáforas multimodais em interações face a face, considerando a modalidade auditiva e a modalidade visual. Partindo da hipótese de que o reconhecimento de uma expressão como metafórica está relacionado com o grau de entrincheiramento 
dessa expressão no sistema conceitual, os autores propõem uma análise de segmentos de um debate presidencial de segundo turno. Da análise dos parâmetros de metaforicidade multimodal, em compostos verbogestuais, os autores extraem a conclusão de que a maior proeminência dos efeitos perlocucionais leva a um aumento no uso de recursos gestuais.

Em seu artigo, Hugo Mari caracteriza, em uma perspectiva processual, metáforas sinestésicas, avaliando as condições sensório-motoras que integram a sua construção. Ao contextualizar, epistemologicamente, a sinestesia como um fenômeno neurofisiológico e sua importância como uma atividade perceptiva multimodal, o pesquisador enfatiza discussões recorrentes sobre o alcance das metáforas sinestésicas, apontando, a partir dos resultados de pesquisa obtidos por esses estudos, restrições para a combinação de determinados tipos de metáforas sinestésicas, que, em uma dimensão interpretativa, intuitivamente, parecem naturais.

Ao adotarem a Teoria da Metáfora Conceptual para investigar como e quando pessoas que vivenciaram um trauma utilizam metáforas para falar e refletir sobre essa experiência, Adriana Costa e Gerard Steen analisam um conjunto de entrevistas realizadas com pessoas que experienciaram mudanças psicológicas positivas após o confronto com situações de vida extremamente adversas. Sob a perspectiva da linguística cognitiva de identificação e análise de metáforas, os pesquisadores selecionam metáforas centrais para emoções ligadas ao trauma e à vida. O artigo apresenta resultados de pesquisa baseados em um modelo analítico que evidencia como sobreviventes utilizam as mesmas metáforas conceituais de maneiras distintas, de acordo com o momento de vida narrado.

Os artigos incluídos na terceira parte deste volume dão, assim, conta da natureza figurativa do pensamento humano, tal como evidenciada pela linguagem ativada em instâncias particulares de discurso. A metáfora conceptual é perspectivada como uma estratégia de pensamento, amodal na expressão, criativa e reveladora da aproximação dos conceitos abstratos ao universo da experiência perceptual e corporificada.

$\mathrm{Na}$ quarta parte deste volume, dois importantes nomes da investigação em Ciências Cognitivas apresentam, em entrevista, algumas das ideias com que ajudaram a consolidar esse domínio científico. Mark Turner, autor, em parceria com Gilles Fauconnier, de uma das teorias mais influentes na área dos estudos de cognição, a teoria do blending (mesclagem ou integração conceptual), fala sobre o contributo dessa proposta para a compreensão dos processos cognitivos humanos, e apresenta alguns dos seus mais recentes desenvolvimentos. Em seguida, Per Aage 
Brandt, precursor do campo de estudo da Semiótica Cognitiva, aborda a origem dessa disciplina, posicionando-a em relação a correntes anteriores da Semiótica e de estudo da mente humana, ao longo do século XX. O investigador defende ainda a relevância do estudo do significado e dos processos da sua construção para a compreensão da forma como pensamos a ainda como partilhamos os conteúdos de pensamento.

O número 34 da Revista Scripta apresenta, por fim, resenhas de duas importantes referências para estudos que, ao investigarem diferentes fenômenos implicados na relação entre linguagem e cognição, adotam a Teoria da Integração Conceptual como fundamento teórico e metodológico. Ao analisarem criticamente as obras The communicative mind: a linguistic exploration of conceptual integration and meaning construction, de Line Brandt (2013) e The Origin of Ideas: Blending, creativity, and the human spark de Mark Turner (2014), os professores e pesquisadores Josiane Andrade Militão e Marco Antônio de Oliveira apresentam ao leitor especializado uma detalhada descrição da organização geral e dos fundamentos epistemológicos a partir dos quais essas duas obras se estruturam. Por se tratar de duas recentes publicações representativas dos campos da Semiótica Cognitiva e da Linguística Cognitiva, respectivamente, as resenhas colocam em evidência fundamentos que também são explorados, no âmbito das entrevistas publicadas neste número.

Para além dos fundamentos teóricos e procedimentos metodológicos que apresentam, os artigos, entrevistas e resenhas publicados, nesta edição temática, oferecem propostas para estudos da linguagem, na interseção com a cognição e o discurso, sugerindo que esses podem assumir algumas diferentes direções de investigação, entre as quais a multimodalidade, a figuração ou a intersubjetividade. Na agenda de estudos interdisciplinares que focalizam a interseção entre linguagem, discurso e cognição essas são direções que vêm ocupando espaço importante. Os trabalhos publicados, neste número, em seu conjunto, permitem revelar o potencial de avanço do conhecimento sobre a mente humana, na interação entre linguagem, cognição e cultura, apontando para a possibilidade e a necessidade de um investimento, cada vez mais amplo e sistemático, em pesquisas que se orientem por abordar essa interseção. 
Referências

BENVENISTE, E. Problemas de linguística geral II. Trad. Eduardo Guimarães et al. Campinas: Pontes, 1989. Original publicado em 1974.

BRANDT, Line. The communicative mind: a linguistic exploration of conceptual integration and meaning construction. Newcastle upon Tyne: Cambridge Scholars, 2013.

DONALD, Merlin. Origens do pensamento moderno. Trad. Carlos de Jesus. Lisboa: Fundação Calouste Gulbenkian, 1999.

MARTINS, Helena. Três caminhos na filosofia da linguagem. In: MUSSALIM, F.; BENTES, Anna Christina (Org.). Introdução à linguística: fundamentos epistemológicos. São Paulo: Cortez, 2004.

TOMASELLO, Michael. Origens culturais da aquisição do conhecimento humano. Tradução de Claudia Berliner. São Paulo: Martins Fontes, 2003. Original publicado em 1999.

TURNER, Mark. The Origin of Ideas: Blending, creativity, and the human spark. New York: Oxford University Press, 2014. 


\section{Dossiê}

Estruturação linguística

e cognição 
